\title{
Health within the Leeds Migrant Roma Community; An Exploration of Health Status and Needs within One UK Area
}

\section{Louise Warwick-Booth', Joanne Trigwell1, Karina Kinsella', Kathryn Jeffreys ${ }^{2}$, Derek Sankar ${ }^{3}$, Marketa Dolezalova ${ }^{3}$}

${ }^{1}$ Leeds Beckett University, Leeds, UK

${ }^{2}$ Leeds City Council, Leeds, UK

${ }^{3}$ Advocacy, Leeds, UK

Email: l.warwick-booth@leedsbeckett.ac.uk

How to cite this paper: Warwick-Booth, L. Trigwell, J., Kinsella, K., Jeffreys, K., Sankar, D. and Dolezalova, M. (2017) Health within the Leeds Migrant Roma Community; An Exploration of Health Status and Needs within One UK Area. Health, 9, 669-684.

https://doi.org/10.4236/health.2017.94048

Received: January 17, 2017

Accepted: April 24, 2017

Published: April 27, 2017

Copyright $\odot 2017$ by authors and Scientific Research Publishing Inc. This work is licensed under the Creative Commons Attribution International License (CC BY 4.0).

http://creativecommons.org/licenses/by/4.0/

\section{(c) (i) Open Access}

\begin{abstract}
Existing evidence shows that many Roma communities have received little attention in relation to their health requirements. Evidence illustrates how Roma communities suffer from poorer health and unhealthier living conditions when compared to majority populations, with their poor health closely linked to wider social determinants. This study explored the health status and associated health needs of the Leeds Roma migrant community, a hard to reach and under-explored group across Europe. Questionnaires $(\mathrm{n}=70)$ and focus groups $(\mathrm{n}=43)$ with Roma community members as well as interviews with health professionals $(\mathrm{n}=5)$ working with them were used. The study found language was a key barrier to accessing health care and understanding health messages. Furthermore, participant's understandings of the health system were hindered by their different experiences within their countries of origin. Self-reports illustrated low mental well-being, high levels of stress and unhealthy lifestyles as common issues. The research also highlighted several wider determinants of health as key concerns within the Roma community including housing, employment opportunities and money. The findings of this study contribute to increasing understandings of this community's health needs, their support requirements and the barriers faced by them. These need to be considered to inform strategies and ways of working as mechanisms to tackle health inequalities and promote health within this community.
\end{abstract}

\section{Keywords}

Roma, Health Needs, Access to Services, Social Determinants of Health, Mixed Methods 


\section{Introduction}

The term "Roma" is used by the European Commission to refer to a number of different groups [1]. The findings of this study relate to the migrant population of Roma resident in Leeds, within the UK, not the indigenous Gypsy and Traveller population. Roma has been migrating to the UK for years but the number of migrants has increased. Firstly through those seeking asylum, and latterly through the enlargement of the EU in 2004 and 2007. There is a lack of data in relation to numbers of Roma resident in the UK and Europe resulting from varying definition and classification systems for race/ethnicity, ethical and legal limitations [2], and reluctance to identify as Roma for fear of stigmatisation [3]. In 2011, the UK Census included Gypsy/Traveller as a top-level ethnicity category however, Roma as a choice was not available [4]. UK population estimates vary between 80,000 and 300,000 [5], with 25,451 Roma assumed to be within Yorkshire and the Humber [4]. A significant number of Roma are located in Leeds within the Harehills [5], Armley and Beeston areas, the location of this study [6]. In the UK, Roma are generally located within fixed accommodation yet their cultural lifestyle and dress may result in them being distinguished from the majority population and experiencing discrimination [7]. Despite the lack of formal information pertaining to the health needs of the European and UK Roma population, there is increasing evidence that poverty is more prevalent within Roma communities compared to majority populations [8]. Roma also have considerable health needs [9] [10]. Both the health and health care utilization of Roma have received scant attention from researchers [10] [11] despite Roma health outcomes likely to be worse than majority populations [12] [13]. Thus, the health of Roma populations is a challenge for health promotion practitioners in light of limited evidence, discrimination and social exclusion [10]. Given the uniqueness of the Roma population, and these issues there is a need for further research in relation to Roma health, particularly to inform the development of health promotion strategies and interventions.

\section{Methods}

A mixed methods study was conducted in 2012 across 3 areas of Leeds, a large city located within the north of the UK, in the Yorkshire and Humber region. The research involved Roma communities in gathering local intelligence, developing trust and garnering data that reflected the views of the Roma community (10. Data collection aimed to identify the local barriers in accessing primary and secondary health care services from the perspective of Roma community members. Wider determinants that had an impact upon health and wellbeing within the Roma community were also explored. Data gathering was viewed as a starting point to inform local health promotion approaches.

\subsection{Data Collection Procedures}

All data collection procedures were undertaken by a Roma bilingual advocate and two Roma volunteers. The research used a mixed method approach includ- 
ing focus groups with Roma community members, interviews with local health professionals and questionnaires again with Roma community members.

\subsection{Quantitative Methods}

A close-ended questionnaire was administered to a sample of 70 Roma community members. The questionnaire consisted of topics such as access to services, awareness of services, lifestyle behaviours, experiences of local areas and language needs. Questionnaires were delivered in Slovak, Czech and Romani within both the Harehills area of the city (cohort 1), and then within the Armley and Beeston areas of Leeds (cohort 2). A total of 70 respondents completed the questionnaire; 44 respondents completed the questionnaire in cohort 1 (Harehills area) and 26 in cohort 2 (Armley and Beeston areas). A full breakdown of sample demographics is provided in Table 1.

The majority of respondents spoke Czech (44.3\%), Slovak (25.7\%) or Roma as their primary language. $90 \%$ of respondents reported speaking at least one other language well. $15.7 \%$ of respondents identified English as an additional language spoken. All respondents were asked to describe their spoken English. Over three quarters of the sample reported to speak "little" or "no" English.

Table 1. Questionnaire respondent demographics.

\begin{tabular}{|c|c|c|}
\hline & & Frequency (\%) \\
\hline \multirow[t]{3}{*}{ Sex } & Female & $47(67.1)$ \\
\hline & Male & $19(27.1)$ \\
\hline & Missing data & $4(5.7)$ \\
\hline \multirow[t]{5}{*}{ Age } & $18-30$ & $18(25.7)$ \\
\hline & $31-50$ & $41(58.6)$ \\
\hline & $51-64$ & $8(11.4)$ \\
\hline & $65+$ & $2(2.9)$ \\
\hline & Missing data & $1(1.4)$ \\
\hline \multirow[t]{4}{*}{ Ethnicity } & Roma & $58(82.9)$ \\
\hline & Vlacho Roma & $7(10)$ \\
\hline & Other & $3(4.3)$ \\
\hline & Missing data & $2(2.9)$ \\
\hline \multirow[t]{6}{*}{ Citizenship status } & British Citizen & $1(1.4)$ \\
\hline & Migrant worker EU & $48(68.6)$ \\
\hline & Migrant worker A2 & $1(1.4)$ \\
\hline & Non EU Migrant worker & $1(1.4)$ \\
\hline & Family Migrant-Permanent residency & $18(25.7)$ \\
\hline & Missing data & $1(1.4)$ \\
\hline \multirow[t]{3}{*}{ Carer } & No & $61(87.1)$ \\
\hline & Yes & $6(8.6)$ \\
\hline & Missing data & $3(4.3)$ \\
\hline
\end{tabular}




\subsection{Qualitative Methods}

Five focus group discussions were conducted in total across all three areas of the city in which Roma were living. The focus groups schedule explored a range of issues including experiences of using services such GPs, doctors and hospitals, lifestyle behaviours such as diet and exercise, experiences of work and income and stress. A total of 43 participants contributed to the focus group discussions. In addition, qualitative interviews with professionals who came into contact with the Roma community through the course of their work were carried out $(n=5)$. The interview schedule explored the views of professionals in relation to the needs of Roma within Leeds, discrimination, and service provision. Efforts were made to sample a cross cutting field of people who had both "hands-on" and more strategic experience of working with the community. Within these 5 interviews, there was representation from GP services, a Roma community activist working within migrant services and people employed within local authority services holding a specific remit to work with Roma, Gypsy and Traveller communities.

\subsection{Data Analysis}

The translated transcripts from the focus groups and interviews were analysed thematically [14]). Themes were agreed by the research team. Quantitative data from the questionnaires was cleaned and imported into SPSS, in order to generate descriptive statistics.

\subsection{Ethical Considerations}

The following practices were adhered to ensure ethical rigour: informed consent (written or verbal consent was obtained from all participants in the interviews); confidentiality and anonymity, no personal identifying information has been used in the reporting of data; secure information management and the maintenance of security via password protected university systems.

\section{Findings}

\subsection{Self-Reported Health}

\subsubsection{Long Term Conditions and Disability}

$30 \%$ of questionnaire respondents stated that either themselves, or a family member living in the same household, had a longstanding illness or disability. Of these respondents, $38.1 \%$ had someone in the household registered as disabled.

\subsubsection{Mental Wellbeing}

Questionnaire respondents were asked "in general how do you feel most days?" Over half (51.4\%) of respondents reported they felt "OK" most days and a further $18 \% .6$ described themselves as "happy" Conversely, $20 \%$ of respondents felt "anxious/stressed", 5.7\% were in "low mood/ down" and 4.3\% "sad" most days.

One focus group participant explained that being unable to work due to ill health was causing great concern and stress leading to poor mental health. They 
explained that within their community there was a fear of disclosing a problem relating to mental health,

"People are worried. They are afraid to speak up, because they think that the English will tell them: 'Well, if you are not happy here, what are you doing here? Go home." (Roma Community Member)

This was further reflected in professional interviews where it was felt that mental health needs were not being addressed due in part to stigma and attitudes toward mental health within countries of origin.

\subsubsection{Lifestyle Behaviours}

\section{1) Smoking}

Overall, $67.1 \%$ of questionnaire respondents were current smokers, $24.3 \%$ non-smokers and $7.1 \%$ ex-smokers. $80.9 \%$ of smokers were smoking more than 10 cigarettes a day. Of those who currently smoked, two thirds (63.8\%) wanted to give up in the future. Figure 1, illustrates how many cigarettes were smoked daily by respondents.

During interviews with professionals from the Roma community, the high mortality of the Roma community was highlighted. It was suggested that lifestyle in the Roma community was different to other communities leading to high rates of smoking and alcohol consumption. Focus group participants did not on the whole perceive smoking to be a large problem,

"P d stop smoking, but why when the medication I take has so many side effects that are bad for me. So how will stopping smoking help me, when the medication, that I have to take for the rest of my life, is killing me?' (Roma Community Member)

\section{2) Alcohol}

Approximately half (51.4\%) of questionnaire respondents reported they consumed alcohol "monthly or less" and a further 40\% "never" drank alcohol. 7.1\% of respondents consumed alcohol 2 to 4 times per month. Participants in the focus groups did not report drinking large quantities of alcohol often. However, some

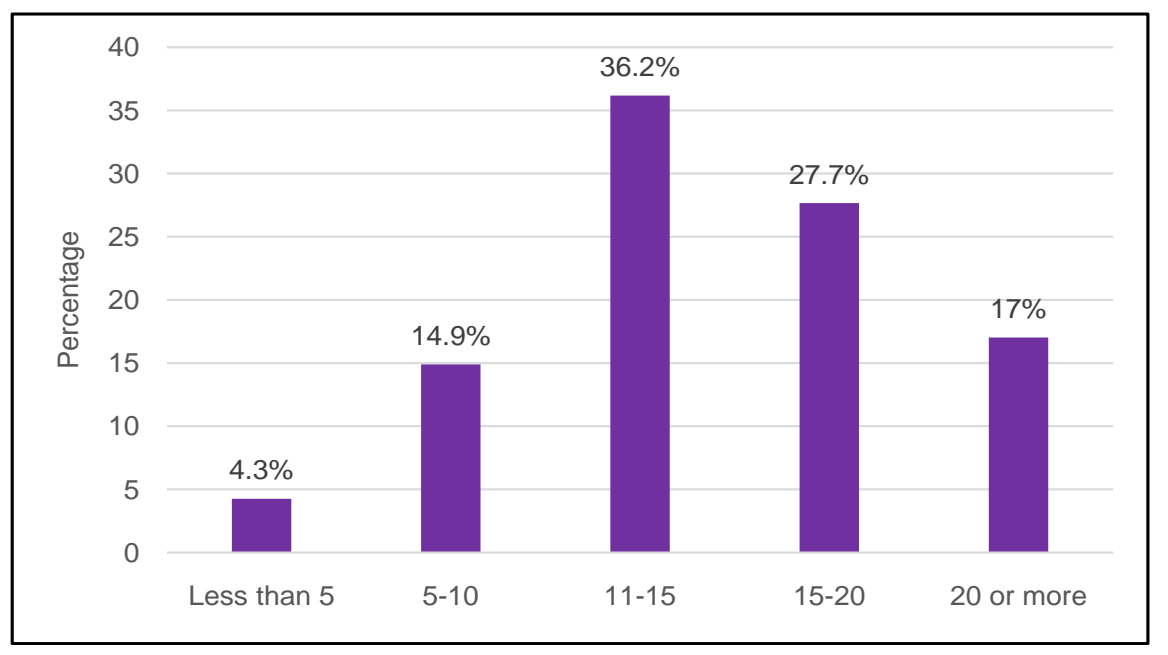

Figure 1. How many cigarettes do you smoke per day? 
did mention having a drink or two every day and it was acknowledged that increased stress levels could lead to alcohol consumption,

"When you' re under some stress, it can have bad effects, because you can start drinking." (Roma Community Member)

\section{3) Fruit and vegetable consumption}

Questionnaire respondents were asked "on a scale of 1 to $5(1=$ very easy, $5=$ very hard), how easy do you find it to get hold of fresh fruit and vegetables?" Over half (54.3\%) of respondents selected 1 or 2 , and just under one quarter choose 4 or 5 . A further $20 \%$ stated 3 .

When asked "yesterday, how many portions of fruit and vegetables did you eat?", only $1.4 \%$ of respondents consumed the recommended daily allowance of 5 or more and $35.7 \%$ consumed none. The majority of respondents $(51.4 \%)$ had 1 to 2 portions.

$70.6 \%$ of the sample who though getting hold of fruit and vegetables was hard (4 or 5), consumed no portions of fruit and vegetables the previous day. However, only 1 respondent (2.6\%) who stated getting hold of fruit and vegetables was easy ( 1 or 2 ) consumed the recommended 5 or more portions the previous day.

The topic of food was also discussed within the focus groups and it was suggested that the participants were not eating the recommended 5 portions per day as their diet was influenced by desire rather than health. It was noted that fruit and vegetables were expensive and that money was required to lead a healthy lifestyle. However, one professional suggested that the Roma community did not understand how to lead a healthy lifestyle. In addition, there was a lack of interest in changing lifestyle behaviours with community members prioritising finding employment, housing and schools for their children.

\section{4) Physical activity}

On average, respondents participated in physical activity at a moderate intensity (heart beating faster and slightly breathless) for 30 minutes 3.4 times a week (range $=0$ to $7, \mathrm{SD}=2.7$ ). $34.3 \%$ of respondents were physically active for 30 minutes 5 or more times a week. Conversely, $18.6 \%$ participated in physical activity for 30 minutes zero times a week (see Figure 2). Moderate physical activity was defined as brisk walking, an activity that most people can do on a daily basis.

The focus group discussions also explored perceptions of health messages with participants reporting suspicions associated with health messages as well as understandings that drinking, smoking and a poor diet were unhealthy. Participants appeared to have strongly held belief systems about these topics,

"I think that if you have a pint a day, it does not cause any harm, for example some people take pills to aid their digestion, but if you have one pint, you wouldn't need the pill." (Roma Community Member)

In a discussion around physical activity participants expressed the belief that your body shape is fixed so exercise and diet have little to play in weight gain,

"Definitely, look at me, I go to the gym, I don't eat sugary food, I have a normal diet. I don't eat fatty or sugary food and I am not slim. She [points to another female] eats everything and she is slim. It doesn't matter [what you do], 


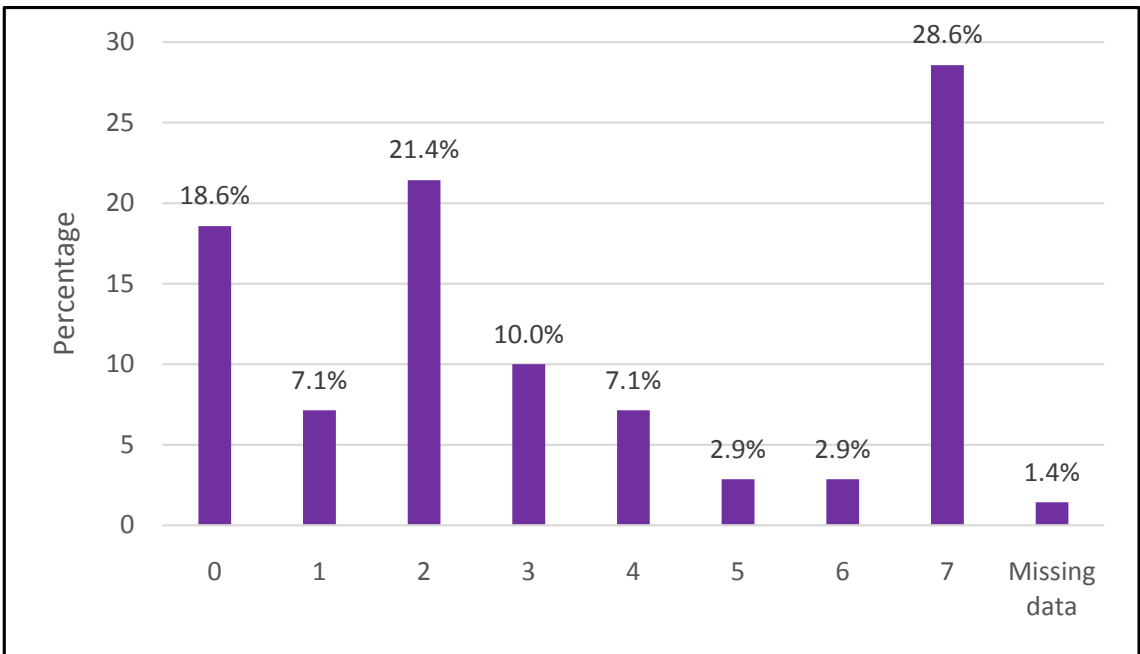

Figure 2. How many days a week do you get 30 minutes of physical activity that makes your heart beat fast and gets you feeling slightly breathless?

\section{I think it is just given. More or less." (Roma Community Member)}

\subsection{Use}

\subsubsection{Seeking Medical Help or Advice}

Questionnaire respondents were asked "when you or a member of your family fall ill and you want medical help or advice where are you most likely to go?" On average, respondents identified 1.4 sources they would turn to (range $=1$ to 3 , $\mathrm{SD}=0.5)$. The most popular source of help was the "GP" (80\%) followed by "friends and family" (37.1\%) and "Accident and Emergency" (12.9\%), illustrated in Figure 3.

Respondents were asked about their awareness of various immunisations services and screening services. Awareness of immunisation services varied; awareness of the childhood immunisation programme (88.6\%) was highest, followed by the seasonal flu vaccination (45.5\%), HPV vaccination (29.5\%) and pneumococcal programme (15.9\%). $6.8 \%$ of respondents were not aware of any vaccination programmes.

Similar to awareness of immunisation services, awareness of pregnancy/ childhood screening programmes was highest (new born screening, 77.3\%; antinatal screening, 59.1\%). Awareness of abdominal (18.2\%) and bowel (20.5\%) screening programmes was the lowest. $18.2 \%$ of respondents were not aware of any of the screening services listed. The majority (75\%) of respondents were not aware of NHS health checks which look at the heart health factors. Only $18.2 \%$ were aware of the checks and $4.5 \%$ were unsure $(2.3 \%$ did not answer the question). When asked if respondents experienced any barriers to accessing the immunisation and screening services the most commonly cited problem was language barriers.

\subsubsection{Access to GPs}

Some focus group participants expressed that they were used to accessing GPs 


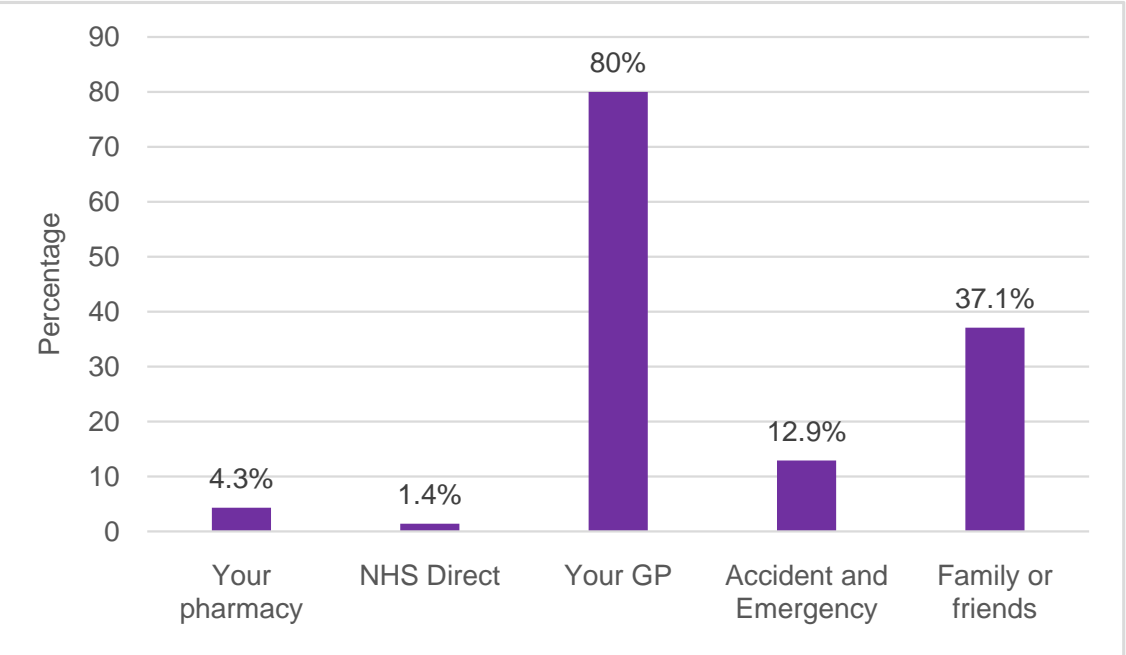

Figure 3. When you or a member of your family fall ill and you want medical help or advice where are you most likely to go?

quickly and found it difficult to adapt to the UK appointment system. Lack of telephone interpreters when booking GP appointments and only being able to book appointments over the phone caused problems with making appointments for some people. Professionals interviewed identified that not understanding the health system and particularly to book into the right kind of slot (emergency versus routine GP appointments) was also a problem and this was compounded by language barriers. Some participants said that in their country of origin it was easy to get a more thorough check up and examination when visiting a GP. A resounding theme that emerged was children not being prescribed medication when presenting with symptoms that the Roma parents considered potentially dangerous. It is not possible to determine from the data whether children are genuinely presenting with viruses for which antibiotics will not help, and the Roma parents do not understand this, or if there is a break down in care. Feelings of not being heard were reported,

"Well, what I do is, when one of the small children is ill, is coughing, I don't take them to the doctors. Why? It's pointless. So we know that nurofen or ibuprofen also has anti-inflammatory effect. So I buy ibuprofen or nurofen and I give them that." (Roma Community Member)

\subsubsection{Use of Hospital Services}

$57.1 \%$ of respondent had used hospital services in the last 12 months, $41.4 \%$ had not. $41.4 \%$ of respondents had accessed the hospital 1 to 2 times, $4.3 \% 3$ to 4 and $11.4 \% 5$ or more. Of those that had used the hospital in the last 12 months, over half (56.1\%) felt the service they received was 'good' and 9.8\% described it as 'excellent'. Conversely, $14.6 \%$ described the service as 'very bad' (2.4\%) or 'poor' (12.2\%) and $17.1 \%$ as ' $\mathrm{OK} /$ indifferent'.

Focus group discussions, involved exploring the use of hospital services. The majority of respondents attributed higher than average levels of use of accident and emergency within the Roma community to perceptions of a lack of exami- 
nation within the GP context, non-referral to specialists and a lack of language support. These perceived issues led to feelings of mistrust and self-diagnosis resulting in direct attendances at accident and emergency services,

$I$ would go to $A \& E$, would have to, there's no doubt, to $A \& E$, yeah, that's the only option." (Roma Community Member)

Positive comments about hospital services focused upon feelings that individuals were treated well, and that doctors were more approachable than 'at home'. Being provided with interpreters and clear directions were appreciated, as was the standard of care. Some participants expressed satisfaction with care provision,

"They treat me and my children very well. I can't complain. Back home, when I used to go ...my little boy...he can't walk, and back home, when I used to go with him to the physio, he was not allowed even just to touch a toy... It's not like that here. He just plays with whatever he likes, they play with him, as they want... They teach him, through play, the exercises that he needs to do." (Roma Community Member)

Whilst there were some negative comments relating to the health care system, participants appreciated having access to free healthcare and exemptions from prescription charges. This meant that many people were able to access treatment that they would not be able to afford in their country of origin.

"All the operations I had to go to with my little boy, and all the tests he's had here... back home, that would cost a fortune...I would never be able to pay for all that back home." (Roma Community Member)

\subsection{Language Needs}

$77.1 \%$ of questionnaire respondents reported "always/ most of the time" $(45.7 \%)$ or "sometimes" (31.4\%) finding language a problem with using health services. Those that experienced language a problem when using health services "always/most or the time" or "sometimes", were most likely to rely on "telephone interpreting" (38.9\%), "family and friends" (33.3\%) or an "interpreter" $(31.5 \%)$ for support when using the health service. A further $9.3 \%$ reported they would most likely rely on a "bilingual advocate". One respondent stated they would rely on 'no-one'.

Respondents from Cohort 1 were asked additional questions regarding language needs and health service (see Figure 4). Specially, 56.8\% of respondents "always/most of the time" understood the advice given to them; $54.5 \%$ "always/most of the time" felt able to ask questions or ask for more information; and $45.5 \%$ felt they "always/most of the time" had a say in decisions made about them. Conversely, $6.8 \%$ of respondents "hardly ever" $(4.5 \%)$ or "never" $(2.3 \%)$ understood the advice given; $11.4 \%$ of respondents stated they "hardly ever" (9.1\%) or "never" (2.3\%) felt able to ask questions or ask for more information; and $18.2 \%$ felt they "hardly ever" (9.1\%) or "never" (9.1\%) felt they had a say in decisions made about them (see Figure 5).

Language barriers were highlighted as a key theme within the focus groups in 


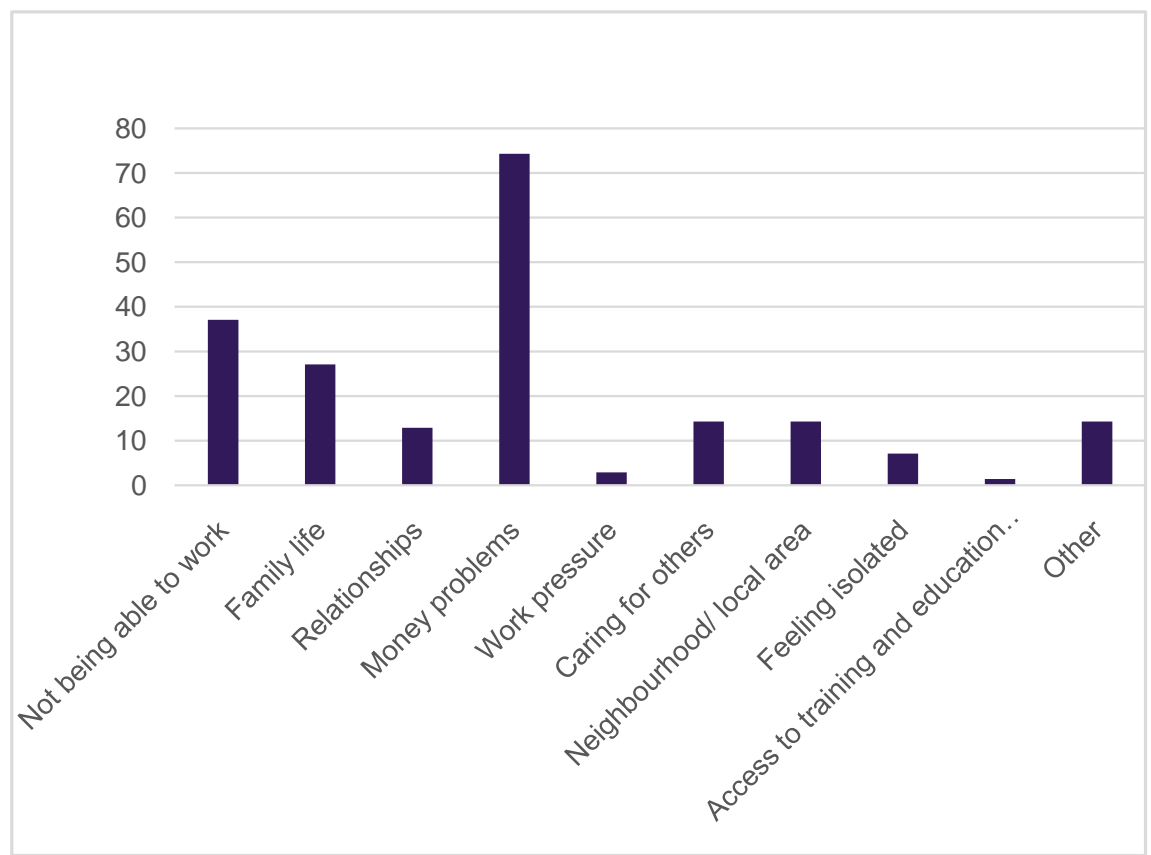

Figure 4. Have any of the following caused you stress in the past year?

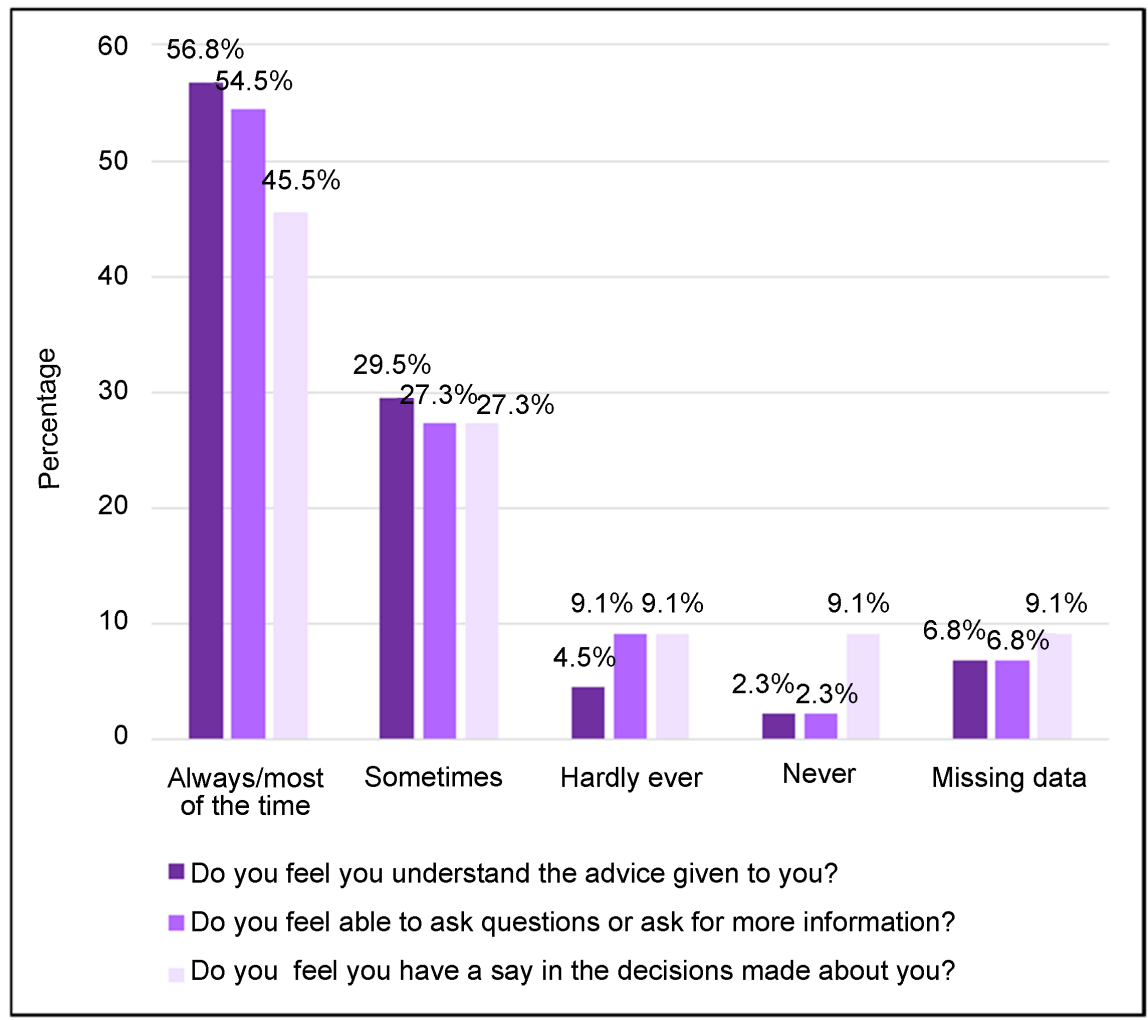

Figure 5. Language needs within health services.

relation to accessing both GP and hospital services. Participants discussed the problems that occur when interpreters are not provided at the point of accessing the GP. Participants felt that this was less of a problem at the hospital although there are still some who described needing more support. It was highlighted that 
a lack of language support led to friends and family members being used as informal interpreters. This was sometimes described by research participants as a stressful process and led to concerns around not understanding what was being said,

"Yeah, with the appointments. I had problems with that, because I don't speak English, they don't give interpreters over the phone, but like, my son can call them so it makes it a bit easier, but not always on the same day. So I would really like to change that." (Roma Community Member)

Language barriers deterred people from being able to describe symptoms or understand diagnosis from the GP. Members of the community indicated they would struggle to explain to the doctor what was wrong with them and even if an interpreter was provided sometimes it was still difficult as interpreters did not always understand medical terminology. Another issue with language support included sending interpreters speaking the wrong language or not interpreting the conversation.

Participants expressed a wish to learn English but faced barriers such as courses aimed at an inappropriate level, having to work when courses were available and childcare,

"Like, I know that it is difficult for some families, for example my wife can't attend courses, because of our children. She's a housewife. But it helped me, I went to college and when I came home, I taught my wife."(Roma Community Member)

Professionals also raised the importance of having command of basic English and the difficulties faced when trying to attend courses where there were no teachers speaking Czech or Slovak.

\subsection{Social Determinants of Health}

Questionnaire respondents were asked to report upon community problems in their area. Issues included isolation, a lack of places for Roma people to meet, no activities for the young, not feeling welcome and lack of knowledge/ services of where to seek help about rights. Street cleanliness was identified as a problem in relation to rubbish, dog fowling, and used needles.

Crime was also reported as a problem with a particular focus upon drug use, vandalism and fear of violence. Cohort 1 were asked about their experiences of crime. $18.2 \%$ of respondents $(n=8)$ had been a victim of crime in the last year. Crimes related to car/ property damage, fraud, theft and verbal abuse. All respondents stated that they had reported the crime; 3 respondents reported the crime to the police. Others reported the crime to: friends and family $(n=1)$, landlord $(n=1)$, school $(n=1)$ and 2 respondents did not identify who they reported the crime to. Of those who had been a victim of crime, $75 \%$ felt it was because of their nationality.

Questionnaire respondents were also asked to report experiences of prejudice and discrimination. $47.7 \%$ of questionnaire respondents did not feel they had, or someone in their family had, faced prejudice or discrimination whilst being in 
the UK because they were Roma. Conversely, $13.6 \%$ reported to face prejudice all the time (6.8\%) or often (6.8\%). 11.4\% reported experiencing prejudice occasionally and $11.4 \%$ hardly ever. Examples of this included verbal abuse/ being threatened, damage to property, mistreatment from professionals and children experiencing problems in school. Discrimination was also discussed within the interviews by a number of the professionals as both service providers and service users. Generally it was felt that the type of discrimination within the UK was different as open discrimination is discouraged. Some focus group members felt health service staff treated them with dignity and respect, and expressed that they felt less discrimination in the UK. However, there was a sense that Roma in Leeds struggle to leave behind their past experiences of feeling unheard, receiving a second class service and discrimination in their country of origin. One participant explained her reluctance to disclose that she was Roma to avoid potential discrimination,

"My daughter goes to school but I don't put her as a Roma, because the Slovak children there would laugh at her. Because Slovak children go there as well. 'Hey, look, Gypsy." (Roma Community Member)

Housing was also identified as an issue within the focus groups and interviews. Professionals explained that many members of the Roma community had to use private landlords who were reluctant to provide facilities, or make repairs to houses. Poor living conditions such as damp and draughty accommodation were believed to be stressful and harmful to health. It was emphasised that housing for Roma was of poor quality, with exposure to dirty properties lacking proper facilities,

"...for over a year, we have damp in our house, water is seeping up from underneath, we went to housing last year, we reported it..." (Roma Community Member)

Finally, unemployment was also noted by questionnaire respondents as a key issue. This also emerged within the focus groups in relation to the difficulty of securing employment. Lack of work and being unable to work alongside the financial difficulties this brought were highlighted as one of the main causes of stress by community members. Work was recognised as important in relation to health and participants indicated they wanted to work. It was acknowledged that finding work was extremely hard and that being able to speak English was a key enabler in this process,

"I would just like to go to work. When you work, everything changes... Work would be best, if I had that, I wouldn't have to think about things. No? When you have a job, you' re better off. If you don't have a job, you' re not entitled to anything." (Roma Community Member)

For women who wanted to work childcare was indicated as a barrier to finding employment,

"I had a chance of working in Tesco but I was disadvantaged because I would have to start at 10 and work until 7. And that was no possible for me because my children come home from school at 3:10 or 3:20" (Roma Community Member) 
Money was discussed within the focus groups and participants expressed mixed levels of difficulty with money, some were able to pay their bills but most struggled to pay everything on time and sometimes fell behind with payments. Paying in instalments or taking out loans were a popular way of managing. Participants discussed trying to spend less and "being careful", food and clothing were the items most likely to be cut back on with children's needs being prioritised,

"Yes, I have to be more careful and spend less, for example I can't buy clothes or household items or something, I have to make do because fridge is something you need to have... you can cut back on food, on clothing, and other things like this."(Roma Community Member)

\subsection{Experiences of Stress}

The majority of questionnaire respondents (91.4\%) reported feeling high levels of stress during the past year, with the most common cause of this being money problems ( $74.3 \%$ of the sample). These categories are similar and overlap but were used in the original questionnaire independently hence are reported separately here. Figure 4 provides a more detailed overview of all reported causes of stress.

Respondents who identified factors that had caused them stress in the last year were asked what they thought could be done to help reduce this. Overall, 79.7\% identified one or more responses to reducing stress (range $=0$ to 5 , mean $=1.9$, $\mathrm{SD}=1.4)$. Over half $(54.3 \%)$ of respondents felt advice surrounding money or benefit entitlement would be beneficial. $65.5 \%$ of respondents who identified money as a stressor (money problems/ ack of money), thought that advice on money/benefit entitlement would be helpful to reduce their stress.

\section{Discussion}

The legacy of Roma history is one of discrimination, hardship, poverty and poor health outcomes [3]. Common issues highlighted within the literature illustrate suspicion of authority figures within Roma communities, extreme poverty, poor living conditions and generally lower life expectancy than population averages [8]. There is a gap in the academic evidence base here, with published research on the health needs of the Roma population being sparse [10]. This research is a useful starting point for enhancing understandings of Roma needs within the UK. Existing evidence shows that many Roma communities have received little attention in relation to their health requirements despite some studies showing that the Roma community suffer from poorer health and unhealthier living conditions when compared to majority populations [3]. This poorer health can be closely linked to the wider social determinants of health [15]. The research findings reported here broadly relate to the existing evidence base in that the wider determinants of health such as employment and housing conditions were reported as key concerns resulting in experiences of stress. Furthermore, other literature points out that access to health care for Roma communities simply 
cannot be discussed without an analysis of poverty, restricted access to education and social exclusion [16]. This research has also provided some insight into the use of health services, Roma community experiences as well as some detail about Roma community needs within one geographical area of the UK. Whilst there were good levels of access to primary health care such as GPs in this study, possibly as a result of the availability of care free at the point of access within the UK, there still remained disproportionally high levels of accident and emergency usage [17]. Language barriers were reported as a significant issue in the research findings. Unhealthy lifestyle behaviours were also commonly reported, reflecting similar findings from European studies in which frequent smoking, lack of physical activity and poor diet are evident, illustrating opportunities for health promotion and prevention activities [18]. However, health cannot always be prioritised within communities that have multiple worries [19], because everyday life and its associated demands shape health and illness [20]. Therefore, maintaining positive lifestyle choices such as sustained weekly physical activity is difficult for many people without the additional problems reported here. Given the influence of social determinants such as employment and housing, health services alone cannot be expected to address these issues within migrant communities [21]. Furthermore, all health promotion interventions need to consider the dynamics of health, income and social position [22]. The health outcomes of Roma are the result of a complex number of influencing factors [23], as this research study is able to demonstrate.

In terms of improving health outcomes and promoting the health of UK Roma several recommendations can be made resulting from the research findings of this study, which fit with existing evidence highlighting the importance of targeted interventions [8]. The existence of language barriers indicates the need for provision of language services, support with literacy and the development of appropriate communication tools. Education about health care provision, points of access and healthy behaviours would also be of use to the Roma community. Interventions should focus upon increasing Roma access and understandings of the nature of services and treatment. Employment assistance for Roma community members should be considered as a mechanism for support and way to begin tackling the wider determinants of health. Finally, localised support would be a useful tool in addressing some of the other needs identified within this research, for example in relation to housing. Given that the Roma community often distrust professionals [8], promoting health within this community is not an easy undertaking.

\section{Conclusion}

This research illustrates that Roma community members require support in a number of areas such as with language, employment and money advice as well as with increasing their understanding of how health services operate. The wider determinants of health were important factors in relation to living conditions and in relation to levels of self-reported stress amongst respondents. Health be- 
haviour data reflected high levels of smoking and low levels of fruit and vegetable consumption. Furthermore, language barriers were reported as a significant issue in relation to accessing health care services. Hence, opportunities exist for specific targeted health promotion within the Leeds Roma community in these identified areas. Further research is required within other UK communities to ascertain if these issues are the same for Roma living within other geographical locations. Finally, any health promotion interventions being undertaken with UK Roma require robust evaluation and reporting to ascertain effectiveness as well as lessons for both policy and practice.

\section{Acknowledgements}

The authors would like to acknowledge Leeds City Council and Advocacy UK for their work on accessing the Roma community and data collection and providing their support to the Leeds Beckett team. We would also like to thank and acknowledge all of those who participated in the research.

\section{References}

[1] European Commission (2012) National Roma Integration Strategies: A First Step in the Implementation of the EU Framework. COM, 133.

[2] Kosa, K. and Adany, R. (2007) Studying Vulnerable Populations: Lessons from the Roma Minority. Epidemiology, 18, 290-299. https://doi.org/10.1097/01.ede.0000258919.15281.4f

[3] Masseria, C., Mladovsky, P. and Hernandez-Quevedo, C. (2010) The Socio-Economic Determinants of the Health and Status of Roma in Comparison with NonRoma in Bulgaria, Hungary and Romania. European Journal of Public Health, 20, 549-554. https://doi.org/10.1093/eurpub/ckq102

[4] Brown, P., et al. (2013) Migrant Roma in the United Kingdom. Population Size and Experience of Local Authorities and Partners. University of Salford, Manchester.

[5] Travellers Health Partnership (2006) Roma Families in Leeds-A Social Audit of Their Situation, Needs and Services. http://www.grtleeds.co.uk/Health/index.html

[6] Morris, M. (2016) Roma Communities and Brexit: Integrating and Empowering Roma in the UK. http://www.ippr.org/read/roma-communities-and-brexit

[7] Staniewicz, T. and Owen, D. (2009) Barriers to Seeking Advice: New Communities in Coventry and Their Experience of Frontline Advice Services. CRED, University of Warwick, Coventry.

[8] Parekh, N. and Rose, T. (2011) Health Inequalities of the Roma in Europe: A Literature Review. Central European Journal of Public Health, 19, 139-142.

[9] Milcher, S. (2006) Poverty and the Determinants of Welfare for Roma and Other Vulnerable Groups in Southeastern Europe. Comparative Economic Studies, 48, 20 35. https://doi.org/10.1057/palgrave.ces.8100148

[10] Hanioff, S. and McKee, M. (2000) The Health of the Roma People: A Review from the Published Literature. Journal of Epidemiology and Community Health, 54, 864869. https://doi.org/10.1136/jech.54.11.864

[11] Adany, R. (2014) Roma Health Is Global Ill Health. European Journal of Public Health, 24, 702-703. https://doi.org/10.1093/eurpub/cku143

[12] Mckee, M. (1997) The Health of Gypsies. BMJ, 315, 1172-1173. 
https://doi.org/10.1136/bmj.315.7117.1172

[13] Zeman, C.L., Depken, D.E. and Senchina, D.S. (2003) Roma Health Issues: A Review of the Literature and Discussion. Ethnicity and Health, 8, 223-249. https://doi.org/10.1080/1355785032000136434

[14] Braun, V. and Clarke, V. (2006) Using Thematic Analysis in Psychology. Qualitative Research in Psychology, 3, 77-101. http://eprints.uwe.ac.uk/11735 https://doi.org/10.1191/1478088706qp063oa

[15] Foldes, M.E. and Covaci, A. (2012) Research on Roma Health and Access to Healthcare: State of the Art and Future Challenges. International Journal of Public Health, 57, 37-39. https://doi.org/10.1007/s00038-011-0312-2

[16] Rechel, B., Blackburn, C., Spencer, N.J., and Rechel, B. (2009) Access to Health Care for Roma Children in Central and Eastern Europe: Findings from a Qualitative Study in Bulgaria. International Journal for Equity in Health, 8, 24-33. https://doi.org/10.1186/1475-9276-8-24

[17] European Roma Rights Centre (2006) Ambulance Not on the Way. The Disgrace of Health Care for Roma in Europe Budapest, European Roma Rights Centre.

[18] Hajduchova, H. and Urban, D. (2014) Social Determinants of Health in the Romani Population. Kontakt, 16, e39-e43.

[19] Koupilova, I., Epstein, H., Holick, J., Hajioff, S. and Mckee. M. (2001) Health Needs of the Roma Population in the Czech and Slovak Republics. Social Science and Medicine, 53, 1191-204.

[20] Gill, G. (2009) The Health Needs of the Slovak Roma Community in Sheffield. Community Practitioner, 82, 34-37.

[21] Minsterio da Saude (2007) Conference on Health and Migration in the European Union (28 September 2007). Minsterio da Saude, Lisbib.

[22] Wilkinson, R.G. (1996) Unhealthy Societies. Routledge, London. https://doi.org/10.4324/9780203421680

[23] Fesus, G., Ostlin, P., Mckee, M. and Adany, R. (2012) Policies to Improve the Health and Well-Being of Roam People: The European Experience. Health Policy, 105, 25-32. https://doi.org/10.1016/j.healthpol.2011.12.003

\section{Submit or recommend next manuscript to SCIRP and we will provide best} service for you:

Accepting pre-submission inquiries through Email, Facebook, LinkedIn, Twitter, etc. A wide selection of journals (inclusive of 9 subjects, more than 200 journals)

Providing 24-hour high-quality service

User-friendly online submission system

Fair and swift peer-review system

Efficient typesetting and proofreading procedure

Display of the result of downloads and visits, as well as the number of cited articles

Maximum dissemination of your research work

Submit your manuscript at: http://papersubmission.scirp.org/

Or contact health@scirp.org 